\title{
English film appreciation: multi-dimensional cultural learning
}

\author{
Xueyan Hu \\ Foreign Languages Department, CTGU, Yichang, Hubei, China
}

Email address:

54784269@qq.com

\section{To cite this article:}

Xueyan Hu. English Film Appreciation: Multi-Dimensional Cultural Learning. International Journal of Language and Linguistics. Vol. 1, No. 4, 2013, pp. 178-181. doi: 10.11648/j.ij11.20130104.22

\begin{abstract}
According to Constructivism Learning Theory, people learn language by collaboration with others in certain situations. It attaches importance to the roles of four principal factors, namely "situation", "collaboration", "dialogue" and "meaning construction" in learning. By watching English films, students' enthusiasm and initiative can be motivated. Students can build their knowledge networks with "English thinking mode". In classroom teaching, teachers can carry out various class activities by using English films as materials to help students build English cultural cognition and enhance their intercultural communication competence.
\end{abstract}

Keywords: Constructivism, Film Appreciation, Multi-Dimensional Cultural Learning

\section{Constructivism Learning Theory}

Constructivism learning theory is a philosophy which enhances students' logical and conceptual growth. The underlying concept within the constructivism learning theory is the role which experiences-or connections with the adjoining atmosphere-play in student education.

The constructivism learning theory argues that people produce knowledge and form meaning based upon their experiences. Two of the key concepts within the constructivism learning theory which create the construction of an individual's new knowledge are accommodation and assimilation. Assimilating causes an individual to incorporate new experiences into the old experiences. This causes the individual to develop new outlooks, rethink what were once misunderstandings, and evaluate what is important, ultimately altering their perceptions. Accommodation, on the other hand, is reframing the world and new experiences into the mental capacity already present. Individuals conceive a particular fashion in which the world operates. When things do not operate within that context, they must accommodate and reframing the expectations with the outcomes.

Constructivism learning theory holds that "People produce subjective understanding of objective things and construct meanings from their experience. It attaches importance to the process of learning and opposes passing on knowledge mechanically" (Williams. 2000:1). According to Constructivism Learning Theory, people learn language by collaboration with others in certain situations. Therefore, Constructivism Learning Theory attaches importance to the roles of four principal factors, namely "situation", "collaboration", "dialogue" and "meaning construction" in learning (He Kekang, 1998). Learning is always related to social and cultural background (i.e. "situations"). By learning under actual situation, students can use relevant experience in their original cognitive structures to assimilate and index new knowledge they just obtained. Therefore, the new knowledge is given a certain meaning. Therefore, the students do not accept knowledge passively from the teachers, but obtain knowledge through meaning construction under certain situations (social and cultural background) with the help of teachers and learning partners by using some necessary learning materials.

Thus, it shows that the core of Constructivism Learning Theory is that "if students want to learn knowledge successfully, they need to discover and transfer complicated information themselves". (Slavin, 2003:188). It means that knowledge is not imparted by teachers, but constructed by students under certain situations through collaboration, discussion, communication and mutual help (including guidance and help of the teacher) with the help of necessary information resources. In education, this theory tells people that "teachers cannot simply impart knowledge to students. What they need to do is to help the students take the initiative to build knowledge" (Slavin, 2003: 188). "The task 
of the teacher is to help and promote this knowledge construction process. Thinking development is closely related to language and experience. The language learning method that depends on memory cannot stimulate deep thinking" (Williams. 2000: 18). Under the guidance of Constructivism, students can solve problems and learn skills in actual problem situations by making interaction with others in social communications.

\section{English Films and Cultural Learning}

Under the guidance of Constructivism Learning Theory, cultural education has the advantages which traditional teaching mode does not have. It provides theoretical basis for discussion of teaching practice of English film appreciation.

Films is the most direct and vivid way to reflect social culture and life of a country or a nation. By watching English films, the viewers can have knowledge of thinking mode, life style, customs, historical tradition and other background information of English-Speaking countries from multiple aspects and angles. Their knowledge of cultural differences between the east and the west can be enhanced; their cross-cultural cognition in language use can be strengthened. For example, by watching the Great Gatsby, people can gain knowledge of rise, flourish and fall of the American dream and the situation of the US in the age of jazz and learn the meaning of existence and national spirit of the American. By watching Forrest Gump, the viewers can learn the spirit of struggle and values of modern American from the loyal, rigid, friendly and tenacious figure - a common person but also a hero; Moreover, from his personal development course from 1950s to $1980 \mathrm{~s}$, the viewers can have a knowledge of development and transformation of the US in that period (from anti-war movement to the life of hippies; from fighting against discriminate to fighting for civil rights; from women's liberation movement to criticism of feminism) (Xiao Qishu, 2010).

In addition, by appreciating English films, the students can learn the importance of non-verbal activities in communication in English-speaking countries such as facial expression, gestures, body language, and hint of tone and dress culture. These elements can hardly be explained by teachers in classes.

According to Constructivism Learning Theory, creating necessary "scenes" in teaching is very important. In traditional cultural education, the teachers teach cultural knowledge in books. It is boring. However, films provide vivid cultural scenes which cannot be provided by the traditional teaching methods. Students can feel the cultural difference directly. Film watching provides a relatively relaxing atmosphere which can stimulate interests and motivation of learning of students. In this way, a series of other mental activities such as thinking and memory can be generated. Learning effect of the students can be greatly enhanced. In addition, if teachers can organize various interactive activities in and out of classes effectively, in the process, students can learn to use and consolidate the language knowledge in real environment and deepen their perceptual knowledge of the language they learn and the culture of the relevant country.

Some scholars also divide learning style of the students into three types, namely audio type, visual type and tactile type. As films have subtitles, dialogues, images and other kinds of information, they can meet requirements of different types of students.

\section{Multi-Dimensional Cultural Learning through Films}

The role of teachers is very important within the constructivism learning theory. Instead of giving a lecture the teachers in this theory function as facilitators whose role is to aid the student when it comes to their own understanding. This takes away focus from the teacher and lecture and puts it upon the student and their learning. The resources and lesson plans that must be initiated for this learning theory take a very different approach toward traditional learning as well. Instead of telling, the teacher must begin asking. Instead of answering questions that only align with their curriculum, the facilitator in this case must make it so that the student comes to the conclusions on their own instead of being told. Also, teachers are continually in conversation with the students, creating the learning experience that is open to new directions depending upon the needs of the student as the learning progresses. Teachers following Piaget's theory of constructivism must challenge the student by making them effective critical thinkers and not being merely a "teacher" but also a mentor, a consultant, and a coach.

According to the film appreciation process, appreciation of film includes four stages, namely "preparation", "entering", "resonant climax" and "aftertaste". While using English films in cultural education, the four stages are corresponding to selection of film, projection, understanding of the film content and explanation and other kinds of activities in and out of class respectively.

\subsection{Creation of Scenes: Selection of Films}

Cultural cognitive competence of the students is trained in all kinds of English classes such as listening, speaking, reading and writing. Therefore, the range of application of English films is wide. While choosing teaching materials from abundant English film resources, the teachers take teachability, learnability and value of the films as well as language, historical culture, aesthetic taste of the film into consideration. Moreover, the films must be able to help students expand their knowledge of western culture and enhance their cultural cognitive competence. For senior class students who have certain language basis and basic comprehensive language use ability, the teachers can choose films with relatively deep philosophical connotations, such as Forrest Gump and a Beautiful Mind. In order to guarantee 
effectiveness of in-class scene creation, the teacher can show the whole film before class and show certain clips again in class.

\subsection{Collaboration and Conversation: Interaction between Teachers and Students in Activities in and Out of Classes}

Before film appreciation, the teacher can give a brief introduction to the historical background, main content and character relations which will help students deepen understanding, draw cultural knowledge, enhance cultural literacy and widen western cultural horizon. In addition, in order to get background information of the film, the teacher can ask students to search information themselves, make induction and summarization and give a presentation in class. The information the student gets through independent study is easier to understand and absorb by him/her.

The visual and audial spaces created by the films are like cultural scrolls which directly reflect the western culture. When watching the film, from performance of the characters and change of scenarios, we can learn backgrounds of the speakers, applicable situations of the language and language taboos caused by cultural differences and obtain many non-verbal communication methods related to English culture in a more vivid way (Lin Hongying, 2010). Therefore, in teaching, teachers can choose some parts of the films which are rich in language activities and have profound cultural connotations and ask students to carry out activities they like such as dubbing and role play. During mutual learning and cooperation, the students can learn connotation of western culture in person.

Major teaching activities that can be carried out include:

\subsubsection{Listening \& Repeating, Imitating and Dubbing}

The teacher can choose a part of the film which has many lines. Firstly, he/she can ask the student to repeat what they have heard and remind the students to pay attention to the pronunciation, intonation, liaisons and weak forms. Then, he/she can turn off the sound and play the clip again and ask the students to dub the film by imitating pronunciation and intonation of the actor/actress according to mouth shape, facial expression and body language of the actor/actress.

\subsubsection{Role play, Story Retelling and Group Discussion}

The teacher can select a part of the film which is rich in character activities, ask the students to watch it repeatedly, memorize the lines and performance of the characters and make role play. In order to increase interestingness of the performance, the teacher can ask girls to play male characters and boys to play female characters. Moreover, if the students deeply understand the plot, the teacher can ask them to retell content of the film to train oral generalization and language organizational capability of the students. Meanwhile, the teacher can organize students to discuss on theme of the film, plot, characters of the figures, relations between the figures, film music, narrative skills, etc. as well as how these factors highlight the film theme and characters of the figure. After asking the students appreciating and analyzing the film from the above aspects, the teacher needs to guide the students to carry out multi-dimensional thinking and train their multi-dimensional thinking capability.

\subsubsection{Reading the Script and Related Materials of the Film-Enhancing Reading Comprehension of the Students}

The teacher can ask students to read the script and work out linguistic difficulties by looking up reference books. As a result, vocabulary of the students can be enlarged. Understanding of film content can be deepened. Meanwhile, the teacher can ask the students to look up background information of the film, character analysis and film reviews, classify and summarize these materials before group discussion or fulfilling the writing assignment. Therefore, scope of knowledge of the students can be enlarged and reading comprehension of the students can be enhanced. This independent learning process can motivate learning interests of the students and let the students obtain the latest information of the language.

\subsubsection{Writing Assignment}

After film appreciation, on the one hand, the teacher can ask the students to summarize plot of the film to enhance their writing ability. On the other hand, the teacher can ask the student to write film reviews to express their impression and analyze characters of the figures. In this way, besides writing ability, independent thinking capability and logic thinking capability of the students can be trained. While giving the writing assignment to the students, the teacher shall ask the students to comment on one or two points of the film, but not every aspect. Priority shall be given to fluency and clearness of the expression of the students.

After class, the teacher shall guide and organize the students to make discussion. The teacher can propose subjects on historical events and cultural phenomena related to the film, shooting skills and other aspects. In this process, the teacher can guide and instruct the students to make class discussion or group discussion. In such student-teacher, student-student interaction, they can inspire each other. The students' cultural perception and critical thinking skills can be effectively trained.

\subsection{Critical thinking: Analysis of English Films}

In teaching process, the teacher can help students recall important scenarios, understand content of the film and comprehend connotation of the film by analyzing representative lines. For example, while watching Forest Gump, the students will have a deep impression of the lines such as "life is a box of chocolate, you'll never know what you are going to eat." and "Jenny and I was like a peas and carrots." The teacher can analyze and explain these lines and help the students gain in-depth understanding of the theme and the connotation of the film.

Moreover, besides analyzing some words and sentences, the teacher can select representative sections of the film. 
Before relaying the section in class, the teacher can explain sentences, phrases, slangs and idiomatic usage of words to enhance the students' understanding of the film and language learning capability of the students. Then, the teacher can design some exercises related to the section to inspire the students. In addition, through class discussion, the students can fully understand and absorb social, historical and cultural content related to characters and plot of the film.

\section{Matters to Be Solved}

Instead of having the students relying on someone else's information and accepting it as truth, the students should be exposed to data, primary sources, and the ability to interact with other students so that they can learn from the incorporation of their experiences. The classroom experience should be an invitation for a myriad of different backgrounds and the learning experience which allows the different backgrounds to come together and observe and analyze information and ideas.

With regard to the teaching method of film appreciation, whether it can succeed or not depends on the function of the teacher to a great extent. In class, the teacher is the organizer, the collaborator and the estimator. Before class, the teacher needs to make the teaching plan according to his/her teaching objects and teaching objectives and make good preparation for the class teaching activities. In class, besides controlling play of the film, the teacher needs to help the students carry out all kinds of activities and encourage and help students to communicate with each other and find answers to questions. After class, the teacher shall make comment on assignment and performance of the students and point out deficiencies of the students on their pronunciation and language capability. The teacher also needs to make comment on their opinions.

In addition, as time is limited in class, the teacher needs to give full play to subjective initiative of the students in knowledge construction. If the teacher can give the complete script of the film to the students as the extensive reading material, he/she can encourage the students to figure out difficult grammar points and words by looking up reference books and ask them to guess meanings of the sentences according to the context. In this way, reading comprehension of the students can be enhanced. Moreover, the teacher can organize students and establish "the English Drama Club". $\mathrm{He} / \mathrm{she}$ can ask the students to adapt the film they like the most into a stage play and give a performance in the school.
In this way, enthusiasm of the students in English learning from films can be motivated.

\section{Conclusion}

Learning theory of constructivism incorporates a learning process wherein the student gains their own conclusions through the creative aid of the teacher as a facilitator. The best way to plan teacher worksheets, lesson plans, and study skills for the students, is to create a curriculum which allows each student to solve problems while the teacher monitors and flexibly guides the students to the correct answer, while encouraging critical thinking.

Constructivism advocates learner-centered study and strengthens the importance of initiative of students to explore knowledge and construct knowledge meaning. Therefore, in cultural education, the ultimate purpose of teaching is promoting cultural cognitive construction of the students by the teacher. The teacher shall regard students as subjects of study and initiative constructor of knowledge meaning and give full pay to English films, enhance English learning interests of the students, help students take active part in class activities, strengthen sensitivity and tolerance of cultural difference of the students and their capability to deal with the cultural difference and help students construct cultural cognition in a more effective way.

\section{References}

[1] Williams, Marion, Burden L. Robert. Psychology for Language Teachers [M]. Beijing: Foreign Language Teaching and Research Press, 2000.

[2] Slavin, R. E. Educational Psychology-Theory and Practice [M]. Pearson Education, Inc. Press, 2003.

[3] He Kekang, Constructivism: Theoretical Basis for Reform of Traditional Teaching (1) [J]. Journal of Subject Education, 1998(3).

[4] $\mathrm{Hu}$ Dongqing, Li Lihua, On the Use of English Films in English Teaching in Colleges and Universities [J]. Film Literature, 2010 (24).

[5] Lin Hongying, Teaching of English Culture based on Film Appreciation [J]. Journal of Minxi Vocational and Technical College, 2010 (4).

[6] Xiao Qishu. On Cultural Transference in Foreign Film Appreciation [J]. Film Literature, 2010 (21). 